Spring 3-28-2017

\title{
ILLiad, Rapid, and an Unmediated Solution to the Interlibrary Loan Textbook Dilemma
}

Erika McNeil

University of Connecticut, erika@uconn.edu

Follow this and additional works at: https://opencommons.uconn.edu/libr_pubs

Part of the Collection Development and Management Commons

\section{Recommended Citation}

McNeil, Erika, "ILLiad, Rapid, and an Unmediated Solution to the Interlibrary Loan Textbook Dilemma" (2017). Published Works. 61. https://opencommons.uconn.edu/libr_pubs/61 
The Version of Record of this manuscript has been published and is available in the Journal of Access Services March 28, 2017 https://doi.org/10.1080/15367967.2017.1299579. 


\section{ILLiad, Rapid, and an Unmediated Solution to the Interlibrary Loan Textbook Dilemma}

\section{Introduction}

Using interlibrary loan to request textbooks has been a topic of conversation for years among interlibrary loan practitioners. The practice is fraught with problems and complications, and there are different perspectives on whether interlibrary loan, traditionally a mechanism for obtaining research and scholarly materials, should be used by students as a mechanism to obtain textbooks. Over the years, many libraries have put textbook policies into place, and, because of the issues and costs involved in the obtaining of textbooks via interlibrary loan, it is becoming a common best practice for libraries to prohibit the borrowing of textbooks in this manner. This is demonstrated in Blackburn and Tiemeyer's (2013) analysis of ARL institutions:

Of these [101 ARL institutions], 50 institutions showed clear indication in either their ILL FAQ or on a library services webpage that ILL service would not order textbooks ... Thirty institutions remained silent on borrowing textbooks through ILL, and six did not provide online access to ILL policies or required user authentication before viewing. Only 14 academic libraries, or $13.8 \%$ of those surveyed indicated they would attempt to fill a textbook request, though 11 of these did include the disclaimer that finding textbooks through ILL can be difficult and the request might not be filled. (p. 9)

Munson and Savage used this review to pursue their own analysis, and with the addition of ILL-L listserv discussions determined: ". . the majority of libraries would not borrow textbooks through ILL" (Munson \& Savage, 2013, p. 193). Until 2014, the University of Connecticut had no real policy about the borrowing of textbooks via interlibrary loan, but it was about this time that we found ourselves confronting what could be termed a perfect storm of problems. In terms of a textbook policy, we had to 
seek safe harbor. The decision to implement a textbook policy caused us to face a myriad of issues, and we initially did not achieve the cost savings that we expected; further, our relationship with patrons seemed to worsen significantly. While the problems and the policy decision were not unique to UConn, we had to find our own path to a solution.

\section{ILL and Textbooks: a History of Headaches}

The problems libraries face when allowing textbook requests for students are numerous. Staff in interlibrary loan offices will tell you tales of students who refuse to bring back textbooks when they come due-the worst overdue fine is most likely not as expensive as the cost of a textbook. In other cases, a student will return the original copy and request another, which, depending on timing and availability, may not be supplied by a lending library. This results in confusion for the patron: why could the library obtain a copy before but not now? Add to this the complications that ensue when a few members of a class may be able to obtain the course textbook, but others cannot; after all, there is only a limited supply at potential lending libraries. Even if owned, a textbook may be on reserve or in use at other universities. Bad feelings, confusion, and deteriorating patron relationships wreak havoc with resource sharing. [Blackburn and Tiemeyer (2013) provide a robust exploration that should not be overlooked by anyone investigating this topic.]

There is also the question of the inherent value of the textbooks themselves. Textbooks are transitory: students purchase a textbook for a class and most likely never use it again. As new editions are written, the textbook has less and less value, and it is unlikely that it can be re-sold at its original price. As the recent Pricenomics (Kopf, 2016) report indicates, the majors with the most expensive textbooks are also the textbooks that have the least resale value (Kopf, Which Major's Books Have the Most Resale Value? 
section). Textbook rental sites now give students the opportunity to rent textbooks at a reduced rate; however, after the rental period the access goes away, and there is nothing to sell back to the bookstore or to another student. Over the years, textbook costs have risen exorbitantly. For example, Senack (2016) of the U.S. PIRG notes "Since 2006, the cost of a college textbook increased by $73 \%$ - over four times the rate of inflation. Today, individual textbooks often cost over $\$ 200$, sometimes as high as $\$ 400 "$ (Senack, para. 2). Using interlibrary loan to request a required textbook had become a logical choice for any student wishing to save hundreds, perhaps thousands, of dollars each year. In most cases interlibrary loan requests are placed at no cost to the student, and materials arrive quickly.

What cannot be overlooked is the significant cost to the university of requesting books through interlibrary loan. Even with a reciprocal agreement or consortium membership, a returnable item comes with costs: return mail, staff time, student processing time, supplies, and more contribute to the expense. According to Mary Jackson (2004), the average cost to obtain a book was $\$ 18.35$ in 1997 and $\$ 17.50$ in 2004 (Jackson, 2004). In a later cost study conducted by Leon and Kress in 2012, the average cost to obtain a book (by study participants) was $\$ 12.11$ (Leon \& Kress, res2012). Serving the textbook needs of the undergraduate and graduate populations of a large research university requires significant funding. Moreover, the cost to the university can be multiplied when one considers the potential loss of revenue to the university bookstore: a textbook obtained via interlibrary loan is a textbook not purchased from the bookstore. In our case, the preferred concept of our Interlibrary Loan department collaborating with collection development or reserves to implement a purchasing program -such as that described by Murphy (2012) or Calcagno and Bowdoin (2012), among others - was a non-starter. Our library monographs purchasing had all but vaporized with drastic budget cutbacks.

\section{UConn: Doing Everything for Everyone Becomes Untenable}


Founded in 1881, UConn is a large, Research One Carnegie Classification, ARL institution with a population of over 32,000 graduate and undergraduate students and a local collection of close to 4 million volumes (ARL Statistics 2013-2014). We have four regional campuses: Avery Point, Stamford, Hartford, and Waterbury, as well as two departmental libraries: the School of Fine Arts Resource Center and Pharmacy. UConn ranks among the top 25 public universities in the nation, with 14 schools and colleges; 113 majors; 17 graduate degrees; and 83 research and professional fields of practice. It has connections to the UConn Schools of Law and Health, and faculty and staff number almost 10,000 . Our document delivery and interlibrary loan volume is high, with a volume of over 81,000 borrowing requests and 30,000 lending requests placed in 2016. Our department of four staff and 27 student workers manages ILLiad borrowing and lending, Scan on Demand, the Request Service (borrowing and lending across the UConn libraries), and stacks operations. We are members of the Boston Library Consortium, RapidILL (including RapidR), the Connecticut Library Consortium, the Eastern Academic Scholars' Trust, the Center for Research Libraries, and IDS Project. When we moved to WorldCat Local in 2012, discovery of resources worldwide became as easy as searching the local catalog, and requests increased $36 \%$ over the next two years. At the same time, UConn was making the move to emphasize STEM; and the rapid rise in textbook costs, particularly textbooks in STEM fields, was quickly rising to the crisis point. One study done by Priceonomics (Kopf, 2015) looked at UVA data from 2015 and determined that STEM classes are among the most costly in terms of textbooks (Cost of the Average Textbook by Major section). Munson and Savage distributed a survey at their own institution, Northwestern University, to "shed light on staff questions and assumptions, while allowing some room to discover previously unknown variables through the use of open feedback fields." (Munson \& Savage, 2014). They learned that "the primary motivators for the [interlibrary loan textbook] requests are expense and academic need"' (Munson \& Savage, 2014, emphasis in original). 
So by 2014 we had a large cohort of students in a university focused on STEM who had the ability to discover and request materials from all over the world, and who were faced with astronomically rising textbook costs. These students were now turning to interlibrary loan in droves, and as requests for textbooks rose, ILL costs went up, and patron battles became more frequent, we knew that we had to do something. Further, an added implication for Connecticut was that our state budget was in crisis and about to be significantly cut in a way that would directly affect the library. We also felt that as a leader in the open educational resources initiative, we were providing students curricular support in a more scalable way. We could no longer be everything to everyone, and the time had come for hard choices.

\section{If it Looks Like a Textbook and Sounds Like a Textbook ...}

In 2014, the UConn Library decided to cease allowing interlibrary loan textbook requests for all patrons across the board. It should be noted that these requests included requests placed via ILLiad only; requests for textbooks owned by another UConn campus were excluded from the policy. Our new policy read: "Library policy restricts the borrowing of textbooks, workbooks, and standardized tests. In special circumstances, faculty may request textbook materials for scholarly and research purposes; however these materials are not meant for classroom use." As can be imagined, the feedback resulting from the abrupt change was quite negative. Our initial cancellation process was a guessing game. It was time-consuming and inaccurate, and we had complications from the start. Our cancellation workflow needed to work with an unmediated ILLiad request process that we had put into place with Rapid. These unmediated requests were either filled by lenders and then shipped to us or not filled by lenders and routed to our unfilled queue. For the books we received, we would analyze each item, making a judgment call as to whether they qualified as a "textbook." This often involved referencing the item's 
ISBN online, or reading the book's description. We looked for direct language of use in course instruction, the use of the word "textbook," or its appearance as a rental. Nothing had changed since Munson and Savage (2013) also considered the trouble of trying to define "textbook": "no absolute definition of a textbook exists ... [t]here is no subject heading or fixed field in a MARC record to indicate if a book is a textbook or not" (Munson \& Savage 2014). If we determined that the item were a textbook, we would notify the patron that the request was cancelled, and we would return the item to the lender; if the request went unfilled, we go through the same process in the unfilled ILLiad queue; if it was judged to be a textbook request, we would cancel the request in ILLiad and notify the patron. Figure 1 outlines the workflow I will label the "Likely Suspects" workflow.

Figure 1 Likely Suspects Workflow.

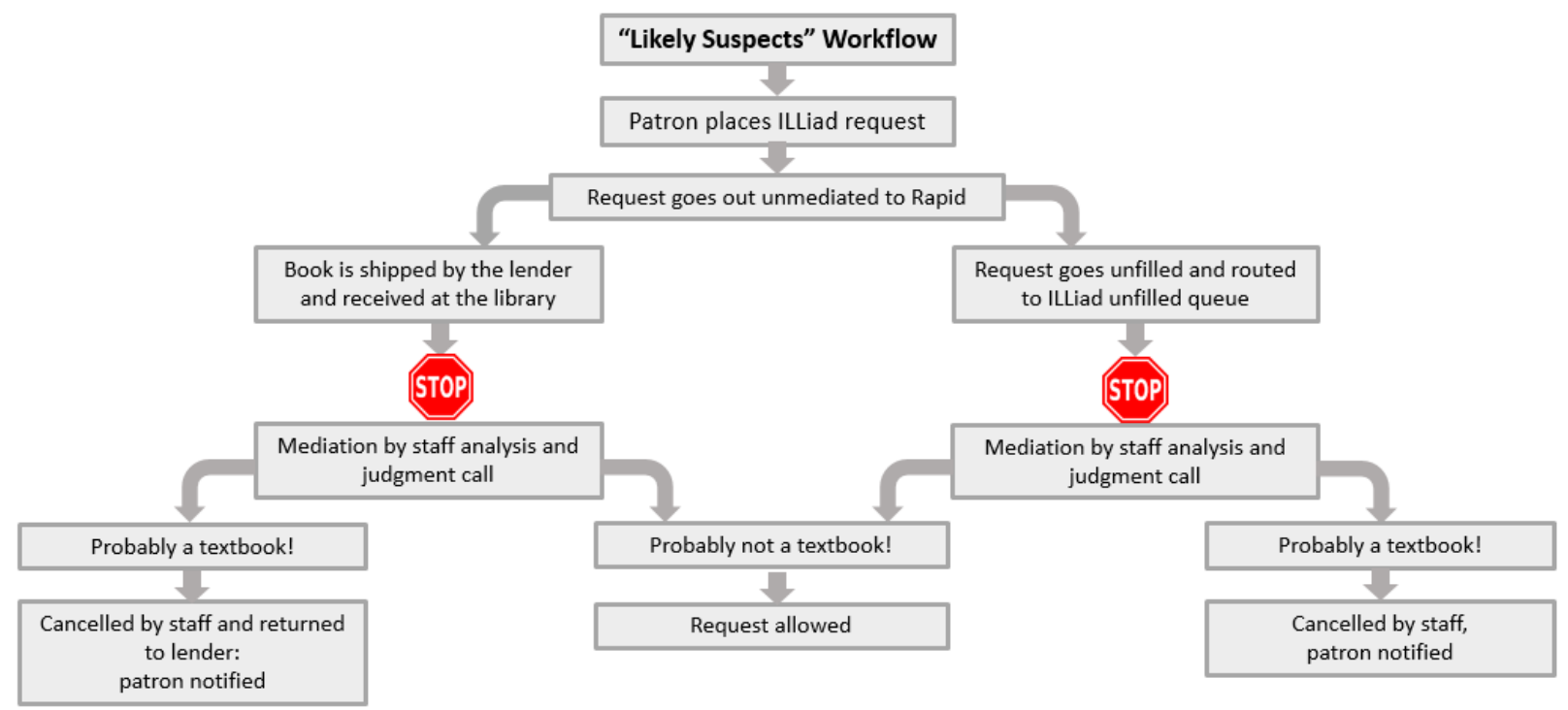

There were clear problems here: we were not saving money on the books that had already been supplied to us, and patrons might know by monitoring their ILLiad account that a lender had provided it. "Textbook" requests were being cancelled, sometimes for items not having been ordered for a class; other classes, many of which were in the humanities, adopted books that did not seem like obvious 
textbooks to us, and those requests were not cancelled. Since we were not able to check each and every book, we focused on what appeared to be "suspects." If we suspected it was a textbook, we looked at it and judged it. We hoped that patrons would become "trained" on our textbook policy. Our thinking was that the word of mouth that had previously communicated that you could get textbooks via ILL would now communicate that you couldn't. Word of mouth was traveling, but it seemed to be communicating the idea that interlibrary loan was not helpful, and that we cancelled patrons' requests capriciously. We had become a victim of the patron dissatisfaction described by Bell and summed up by Blackburn and Tiemeyer: "How a library develops its textbook policy can directly affect student satisfaction with the library. . " (as cited by Blackburn \& Tiemeyer, 2013, p. 8). They were not satisfied. However, in the "likely suspects" time period of January 2014 through September of 2015, we cancelled 680 "textbook" requests. Taking the average cost of an ILL to be $\$ 12.11$, this translated to a savings of $\$ 8,234$. Our cost savings mission was accomplished, but at the expense of accuracy, consistency, staff mediation, and patron satisfaction.

Our new policy did elicit conflicted feelings for staff. It could be argued that in theory a university has an obligation to support students by obtaining access to materials they require for their educational experience. Textbook requests are not prohibited under the ILL Code of the United States; rather, this type of request is identified under the Explanatory Supplement under Special Requirements:

Because returnable materials borrowed via interlibrary loan are traditionally intended for individual use of a defined duration, the requesting library should communicate with the supplying library in advance if the material is needed for other uses, such as course reserves, classroom or other group viewing of audio-visual material, or for an extended loan period, especially of a textbook. (American Library Association, 2016) 
The library needs to and wants to support its patrons, but to anyone in the ILL practice, the issues with textbook support are obvious. So the question for UConn was, how do we balance the need to serve our patrons in their educational pursuits while navigating the problems, concerns, and costs incurred with allowing textbook requests through interlibrary loan?

Our textbook policy continued to generate more negative feedback than we had imagined, and we received many angry emails-including one notorious email from a research assistant that had the heading "How to make education worse and still make money in administration," (name withheld, personal communication, March 26, 2014) as well as phone calls from patrons. Even in the library, staff had their ongoing doubts about the policy, and, unlike ILL staff, circulation desk staff had to deal with irate patrons face-to-face. Liaisons were sharing feedback they received from the faculty. We were in a quandary: we had to continue based on the cost savings, but we also needed to make some adjustments, and soon. We needed a solution that would allow us to save staff time, keep books from being shipped to us, and allow us to seamlessly and accurately align the workflow with our policy. We did not know how close we were to developing a procedure that allowed us to follow our policy and streamline operations, all the while cutting costs. The solution arose in an area staff meeting in September 2015, when one staff member asked a simple question: can Rapid do it?

\section{Course-Adopted Text vs. Textbook: Rapid Knows the Difference}

RapidILL is a resource sharing system designed by the interlibrary loan staff at Colorado State University Libraries to allow for a fast and cost-effective mechanism to share resources. As a Rapid member, we had already experienced the amazing turnaround time of article delivery, and as a Boston Library Consortium member we had recently begun lending returnables under the new RapidR program (UConn 
was one of the original pilot libraries for the program). We had also been utilizing Rapid to return requests to us that our patrons made for materials that were owned and accessible by UConn. Could Rapid also somehow return requests that our patrons placed for texts used in courses?

The first thing we did was look closely at our policy and rethink our definition of "textbook." Not everything that calls itself a textbook is adopted for a course; not every book adopted for a course calls itself a textbook. What if we decided to drop the term "textbook" from our policy and mindset, and move to the term "course-adopted text"? This would more adequately meet the goal we were trying to accomplish: to cancel requests students made for texts being used in their courses. We decided to define textbooks as the actual texts ordered for UConn classes, or course-adopted texts. Using course lists and moving to the term of "course-adopted texts" turned the textbook policy on its ear. Leaves of Grass, Livestock Feeding, and Introduction to Data Analysis were all now on the same playing field. It also allowed us not only to take the personal judgment out of the process, but also to take out the mediation.

\section{Rapid and Course-Adopted Texts: Workflow Simplicity}

We began our new program in October 2015. First, we obtained the list of textbooks ordered for all UConn classes across the main and regional campuses. We then created a master spreadsheet that was narrowed down to include only the titles and ISBNs and submitted this to Rapid. Our systems librarian created a dummy, suppressed catalog record to match on the call number of "TextBook" (Appendix A). We then set up two ILLiad routing rules: one for students and one for faculty and staff (Appendix B). Once this had all been put into place, imagine our satisfaction as requests began returning to us, identified as UConn course-adopted texts, unmediated. 
We decided to make another major policy adjustment. Based on common sense, as well as on continued faculty feedback, we refined the relevant patron groups. It had become time consuming to consider policy exceptions for unhappy faculty members who contacted us to ask for exceptions, and we were always allowing the exceptions when asked. We decided that faculty would most likely not be using textbooks in a class and would instead be using them for research purposes, so we made the decision to put the new policy in place for graduate and undergraduate students only; faculty and staff would be exempt, as the policy did not apply to them. Figure 2 gives our final workflow for course-adopted text cancellations. It should be noted that the list supplied by the bookstore is updated and resubmitted to Rapid on a regular, as-needed, basis, and while we capture the majority of course-adopted texts ordered for the bookstore, we may never have a totally complete and comprehensive list. It should also be noted that we began this process with a locally owned Co-Op system and we did have concerns about our new workflow with the bookstore once it was bought by a large nationwide bookseller; however, we were able to obtain the same reports from them.

Figure 2 Course-Adopted Texts Workflow.

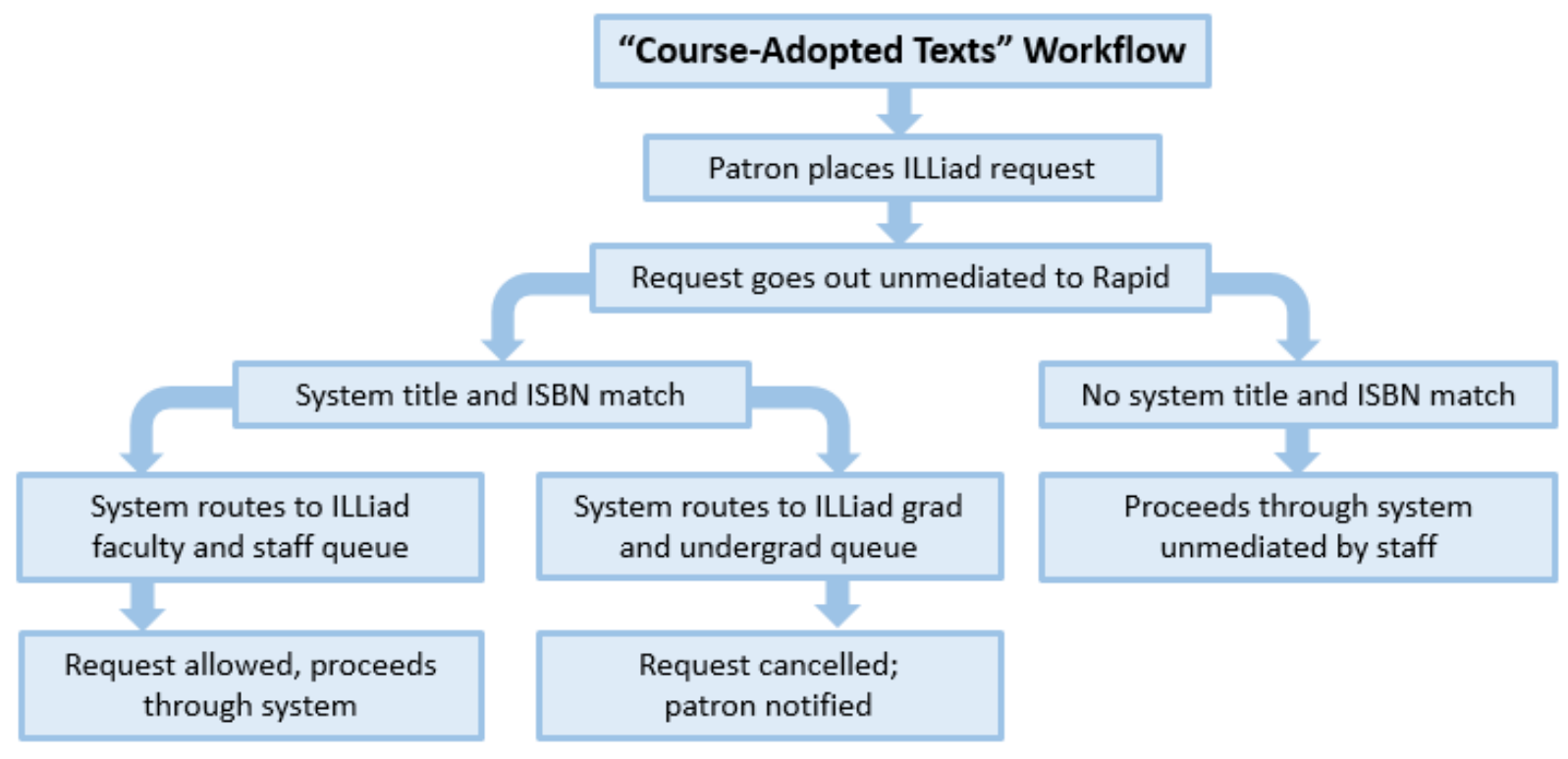


Overall, cancellations increased by $122 \%$ after the change to Rapid and the course-adopted text process, despite faculty exemption, based on a two-year sample (see Figure 3). From October 2014 through September 2015, we had 152 student "textbook" cancellations, which translated to a cost savings of \$1,840; from October 2015 through September 2016, we had 338 student "course-adopted text" cancellations, which translated to a cost savings of $\$ 4,093$. The new process brought an increase in cancellations, and cost savings were up $122 \%$.

Figure 3 Student Textbook Cancellations by Year.

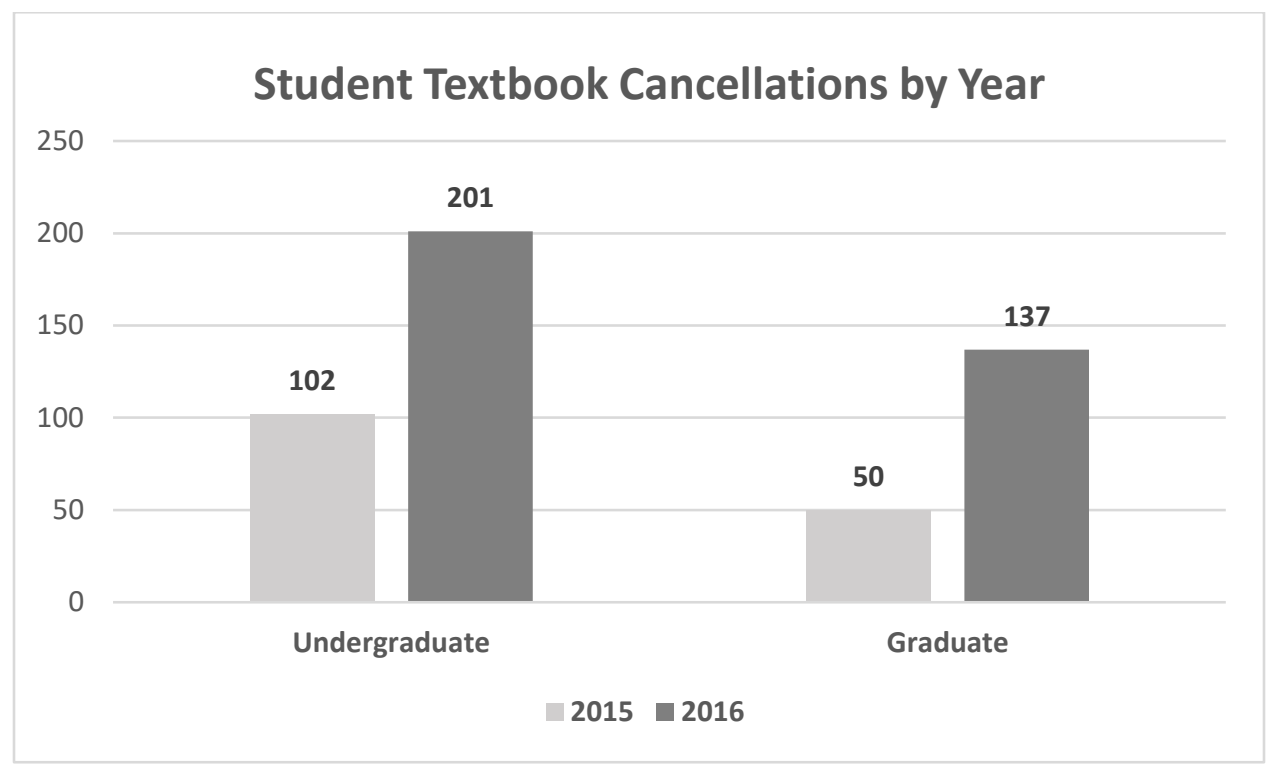

The new process had additional benefits. The process was almost entirely unmediated (with the exception of submitting lists to Rapid, and of cancelling and sending a notification to the patron); items were no longer being shipped to us; cancellations were occurring across all disciplines in a consistent fashion; cancellations were not taking place for books that were not ordered for classes; and we had a new, more positive relationship with our bookstore, as well as with faculty and staff. Our new revised "course-adopted text" policy read: 
The Library restricts both undergraduate and graduate students from borrowing workbooks, standardized tests, and course-adopted texts (for example, textbooks that are currently required in UConn courses). Faculty and staff are permitted to borrow materials required for UConn courses (including textbooks), but only in support of research and scholarly purposes and not for classroom use.

Since implementing the Rapid workflow, we have received almost no negative feedback. Illustrated in Figure 4 is a side-by-side comparison of cancellations across disciplines in the two year sample; this illustrates the general increase of cancellations in the humanities, a discipline that sees an advantage in the Likely Suspects workflow.

Figure 4 Sample of Data Change Across Disciplines. 
Sample of Data Change Across Disciplines

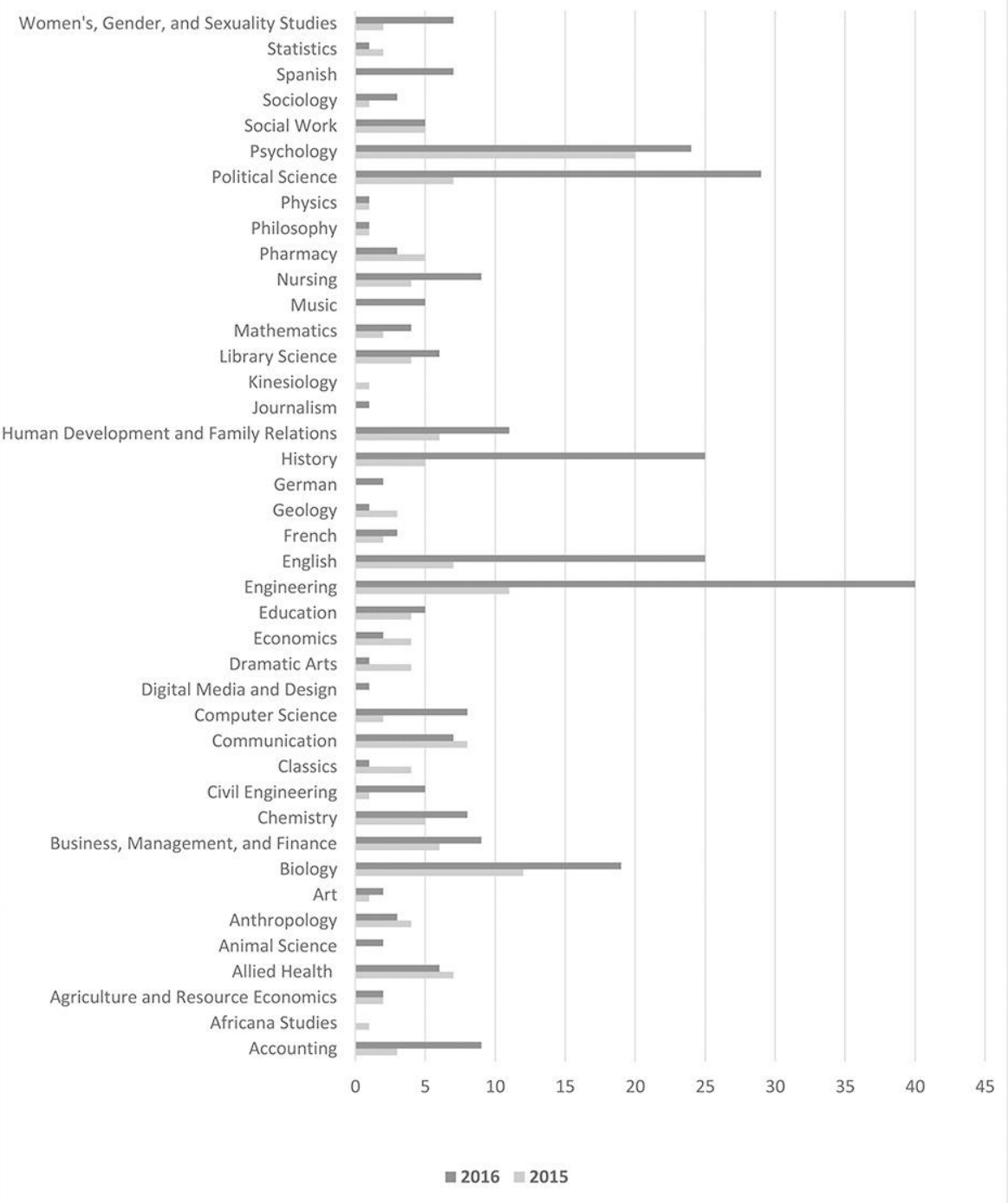

Patterns evident in Figure 5 demonstrate that cancellations occur parallel with the academic calendar which further supports that the cancellations are appropriate.

Figure 5 Textbook Cancellations by Month. 


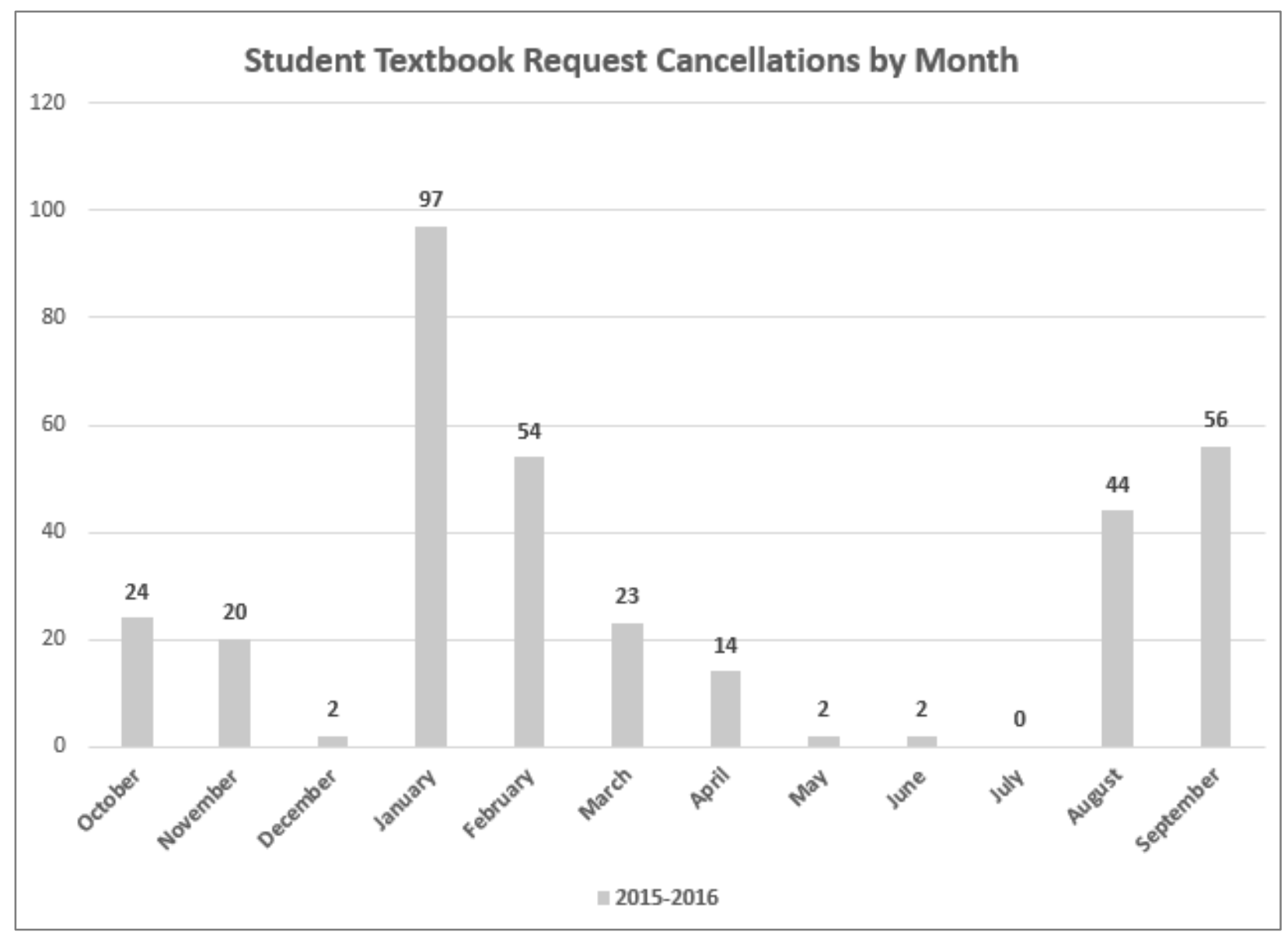

\section{Conclusion}

Overall, the shift in defining what constitutes a "textbook" made all the difference for cost savings, process improvements, and our ability to cancel requests for course-adopted texts equally across all disciplines. No one could argue with us whether a book was being used for a class. Further, as our library moves to align itself with our Law School Library and Health Center Library, we were now able to add textbooks ordered for those classes to our course-adopted report as well. Using Rapid as our mechanism for course-adopted-text requests in ILLiad allowed for complete unmediation of the process, as well as the ability to refine and customize. This was particularly useful to us, as the UConn system at the time of 
moving to Rapid utilized a decentralized bookstore operation. The ongoing battle with patrons for books they refused to return until the end of the semester has been reduced to an occasional skirmish, and we have achieved significant cost savings. Most of all, our decision making is now based on actual data rather than on subjective, staff-mediated judgment calls, saving staff time, money, and headaches. 


\section{References}

American Library Association. (2016). Interlibrary loan code for the United States Retrieved from http://www.ala.org/rusa/guidelines/interlibrary

Bell, S. (2010). Textbook turmoil: the library's role in the textbook revolution. Library Issues, 31(1). Blackburn, G., \& Tiemeyer, R. (2013). “Textbooks and interlibrary loan”. Journal of Interlibrary Loan, Document Delivery \& Electronic Reserve, 23(1), 5-18. doi:10.1080/1072303X.2013.769040

Calcagno, T. M., \& Bowdoin, J. (2012, June). Meeting the textbook needs of engineering students. Paper presented at 2012 ASEE Annual Conference \& Exposition. San Antonio, Texas. https://peer.asee.org/21685

Jackson, with M., Kingma, B., \& Delaney, T. (2004). Assessing ILL/DD services: new cost-effective alternatives. Association of Research Libraries Retrieved from https://archive.org/stream/assessingillddse00jackrich/assessingillddse00jackrich_djvu.txt

Kopf, D. (2015, August 24). Which major has the most expensive textbooks? [Blog post]. Priceonomics. Retrieved from https://priceonomics.com/which-major-has-the-most-expensive-textbooks/ Kyrillidou, M., Morris, S., \& Roebuck, G. ARL Statistics. (2013-2014). Retrieved from http://publications.arl.org/ARL-Statistics-2013-2014/

Leon, L., \& Kress, N. (2012). Looking at resource sharing costs. Interlending \& Document Supply, 40(2), 81-87. doi:10.110802641611211239542

Munson, K., \& Savage, D. (2014). Interlibrary loan's efficacy in meeting students' expectations to acquire textbooks: results from a study conducted in a large research library. Journal of Interlibrary Loan, Document Delivery \& Electronic Reserve, 23(4-5), 191-200.

doi:10.1080/1072303X.2014.890151 
Murphy, M. (2012). Textbooks on reserve: a case study. Journal of Access Services, 10(3), 145-152. doi:10.1080/15367967.2013.795429

Senack, E. (2016, February 3). Student group releases new report on textbook prices. U.S. PIRG. Retrieved from http://www.uspirg.org/news/usp/student-group-releases-new-report-textbookprices 


\section{Appendix A}

The three-part catalog record in Alma:

1. The bibliographic record:

\begin{tabular}{|c|c|c|c|c|}
\hline ans id & 99420441899702432 & nite & Dummy testbook recond for RAPID Z39.50 & \\
\hline Suppress from puolisting & Yes & Export to Worlecat & Publish Biblographic records & Brief level \\
\hline Recerd format & marc21 & & & \\
\hline \multirow[t]{8}{*}{ Originating system } & OIUCT_STORRS & Originating system 10 & 99420441899702432 & Originating System Version \\
\hline & LDR C0249nam a2200097 u 4500 & & & \\
\hline & 00199420441899702432 & & & \\
\hline & $00315092482013 \times x$ r 0000 eng d & & & \\
\hline & $\operatorname{Cos} 20150924085008.0$ & & & \\
\hline & 090 _ la TextBook & & & \\
\hline & 24500 la Durnmy teotbook recond for RAPD 239.50 & & & \\
\hline & 500 _ la DO NOT DELETE! & & & \\
\hline
\end{tabular}

2. The holdings record, with library, location, and call number:

MMS ID 22443937000002432

Brief level 01
Title Dummy textbook record for RAPID Z39.5 Record Format marc21_holding
LDR $00137 \mathrm{nx}$ a22000611n 4500
008 1011252u 8 4001uueng0000000
00520150924085255.0
85280 |b HBL |c stack |h TextBook

3. The item record. The only information it contains is a dummy barcode:

\section{Resource description Dummy textbook record for RAPID Z39.50 2013}

Holding Babbidqe Library: Stack: TextBook

Barcode 20150924085200

Process type -

\begin{tabular}{|c|c|c|c|c|c|c|c|}
\hline mary & \multicolumn{2}{|c|}{ General Information } & ENUM/CHRON information & & Notes & \#: & Histc \\
\hline \multicolumn{5}{|c|}{ Barcode 20150924085200} & & & \\
\hline & Material type & & & & $\nabla$ & & \\
\hline
\end{tabular}

\section{Appendix B}

Routing rule for course-adopted text requests placed by students: 
ProcessType: Borrowing

TransactionStatus: Awaiting RAPID Local Request Processing

Matchstring: t.ILLNumber is NULL and t.CallNumber='TextBook' and (u.status in

('Undergraduate','Graduate'))

NewProcessType: Borrowing

NewTransactionStatus: Awaiting Textbook Title Cancellation

Routing rule for course-adopted text requests placed by faculty and staff:

ProcessType: Borrowing

TransactionStatus: Awaiting RAPID Local Request Processing

Matchstring: t.ILLNumber is NULL and t.CallNumber='TextBook' and (u.status in ('Faculty','Staff'))

NewProcessType: Borrowing

NewTransactionStatus: Awaiting Rapid Local Sending

\section{Appendix C}

Notification template and ReasonforCancellation.

Notification template:

Dear <\#User.FirstName>,

Thank you for your request. Unfortunately, we are unable to meet this request through Interlibrary Services. As a result, the request has been cancelled. <\#Special.CancellationNote>

Title: <\#Transaction.LoanTitle>

Author: <\#Transaction.LoanAuthor>

Date: <\#Transaction.LoanDate>

Publisher: <\#Transaction.LoanPublisher>

Edition: <\#Transaction.LoanEdition>

ISSN/ISBN: <\#Transaction.ISSN>

UConn WorldCat Accession Number: <\#Transaction.ESPNumber>

If you have any questions about this cancellation, please contact our office at udoc@uconn.edu with this transaction number <\#Transaction.TransactionNumber>.

Thank you!

Interlibrary Services

Homer Babbidge Library

University of Connecticut

369 Fairfield Way, U-1005F

Storrs, CT 06269

udoc@lib.uconn.edu

Learn more about us: http://lib.uconn.edu/services/document-delivery-interlibrary-loan/

Reason for cancellation: 
This is due to the Library's policy regarding course materials (http://goo.gl/xHF9mg). If your request was placed to meet a research need, you may wish to contact a subject specialist to discuss the alternatives available to you: http://goo.gl/rRbg9C. 